INTEGRITAS : Jurnal Pengabdian

Vol 4, No 1, Juli 2020

ISSN 2580 - 7978 (cetak) ISSN 2615 - 0794 (online)

\title{
PEMBERDAYAAN PEREMPUAN DALAM MENINGKATKAN KEAKSARAAN USAHA MANDIRI
}

\section{EMPOWERMENT OF WOMEN IN INCREASING INDEPENDENCE OF INDEPENDENT BUSINESS}

\author{
Hastuti ${ }^{1)}$ Lia Hanifa ${ }^{2)}$ \\ ${ }^{1}$ Dosen Program Studi Manajemen \\ ${ }^{2}$ Dosen Program Studi Akuntansi \\ Universitas Muhammadiyah Buton \\ 1Email: tutie977@gmail.com
}

\begin{abstract}
Abstrak: Pemberdayaan Perempuan Dalam Meningkatan Kewirausahaan Usaha Mandiri adalah bentuk layanan program untuk melestarikan keaksaraan dengan memberdayakan masyarakat perempuan melalui kewirausahaan. tujuan utama dari program ini adalah meningkatkan keberdayaan perempuan buta aksara usia 15-59 tahun, melalui peningkatan pengetahuan, keterampilan, sikap dan berusaha secara mandiri. Dalam hal ini masyarakat di berikan keterampilan guna untuk mengembangkan potensi sumber daya manusia yang ada sehingga masyarakat menjadi berdaya. Pemberdayaan perempuan melalui program Keaksaraan Usaha Mandiri dalam proses kegiatan pembelajarannya menekankan pada pendidikan keterampilan yang berpeluang menjadi suatu bidang usaha yang sesuai dengan minat dan potensi yang dimiliki oleh warga perempuan.
\end{abstract}

Kata kunci: Pemberdayaan, Keaksaraan usaha mandiri

\begin{abstract}
Abstrack: Empowering Women in Enhancing Entrepreneurship Independent Business is a form of program services to preserve literacy by empowering women through entrepreneurship. The main objective of this program is to increase the sustainability of illiterate women aged 15-59 years, through increased knowledge, skills, attitudes and independent encouragement. In this case the community needs help to develop existing human resources so that the community becomes empowered. Empowering women through the Mandiri Business Literacy program in the learning process emphasizes the education of skills that have opportunities in the business fields that are in accordance with the interests and potential needed by women citizens.
\end{abstract}

Keywords: Empowerment, Literacy of independent business

\section{PENDAHULUAN}

Dalam rangka pemberantasan buta aksara dan meningkatkan pendapatan masyarakat telah dilakukan untuk menguasai ragam keaksaraannya dan diarahkan untuk menguasai ragam keaksaraan melalui program Pemberdayaan Perempuan Dalam Meningkatkan Keaksaraan Usaha Mandiri.

Keaksaraan usaha mandiri adalah kemampuan membaca, menulis, berhitung, mendengarkan dan berbicara untuk mengkomunikasikan teks lisan dan 


\section{INTEGRITAS : Jurnal Pengabdian}

Vol 4, No 1, Juli 2020

ISSN 2580 - 7978 (cetak) ISSN 2615 - 0794 (online)

tulisan dengan menggunakan aksara dan angka dalam bahasa Indonesia. Keaksaraan usaha mandiri merupakan kemampuan atau keterampilan dasar usaha yang dilatihkan melalui pembelajaran produktif dan keterampilan bermata pencaharian yang dapat meningkatkan keaksaraan dan penghasilan, baik secara perorangan maupun kelompok sebagai salah satu upaya penguatan keaksaraan sekaligus pengentasan kemiskinan.

Program Keaksaraan Usaha Mandiri (KUM) merupakan kegiatan peningkatan kemampuan keberaksaraan bagi warga belajar yang telah mengikuti dan atau mencapai kompetensi keaksaraan dasar, melalui pembelajaran keterampilan usaha (kewirausahaan) yang dapat meningkatkan produktivitas warga belajar, baik secara perorangan maupun kelompok sehinggga diharapkan dapat memiliki mata pencaharian dan penghasilan dalam rangka peningkatan taraf hidupnya (Hening Ratri, 2015).

Tujuan dari Keaksaraan Usaha Mandiri adalah meningkatkan partisipasi perempuan berusia 15-59 tahun yang berkeaksaraan rendah dalam mengikuti kegiatan keaksaraan usaha mandiri. Meningkatkan keberdayaan penduduk usia 15-59 tahun yang berkeaksaraan rendah melalui peningkatan pengetahuan, sikap, dan keterampilan serta berusaha secara mandiri. Memelihara dan melestarikan tingkat keberaksaraan penduduk melalui kegiatan ragam keaksaraan.

Keaksaraan usaha mandiri adalah model pembelajaran pemberantasan dan penguatan keaksaraan warga belajar dengan menggabungkan muatan materi pokok membaca, menulis, berhitung yang terangkum dalam keaksaraan usaha mandiri, dengan materi penunjang yaitu keterampilan fungsional berbasis pada minat, kebutuhan dan potensi pasar/peluang pasar (Nurwahidah, n.d.).

Keaksaraan Usaha Mandiri berupa pelatihan membaca, menulis, berhitung dan mendengarkan. Kondisi seperti ini akan diberikan sentuhan akademik dalam bentuk kecakapan hidup (life skill) berupa keterampilan ekonomi kreatif berupa kerajinan untuk meningkatkan pendapatan.

Sekarang perempuan dituntut aktif secara ekonomi, meskipun disisi lain ada juga tuntutan agar perempuan yang berkeluarga dapat menghasilkan uang tanpa 


\section{INTEGRITAS : Jurnal Pengabdian}

Vol 4, No 1, Juli 2020

ISSN 2580 - 7978 (cetak) ISSN 2615 - 0794 (online)

mengganggu fungsinya sebagai istri dan ibu rumah tangga. Saat ini fenomena perempuan bekerja bukan lagi barang aneh dan bahkan dapat dikatakan sudah merupakan tuntutan bagi perempuan untuk berpartisipasi dalam dunia kerja, yang dapat menaikkan harkat perempuan, yang sebelumnya selalu dianggap hanya sebagai pengurus anak, suami dan rumah tangga semata-mata (Nainggolan, 2013).

Perempuan sebagai warga negara yang memiliki hak dan kewajiban yang sama dengan laki-laki, namun dalam bidang pendidikan dan ekonomi, banyak perempuan Indonesia yang tidak memiliki kemampuan memperoleh peluang kerja karena keterbatasan atau tidak bisa mengolah potensi yang ada pada dirinya maka perlunya pemberdayaan perempuan (Karwati, 2017).

Pemberdayaan merupakan salah satu wadah yang dijadikan sebagai upaya untuk memberikan wahana bagi masyarakat dalam memenuhi akan kebutuhan warga belajar berupa pengetahuan dan keterampilan yang berkaitan bagi kehidupan yang lebih baik di dalam kehidupan keluarga dan masyarakat (Karwati, 2017).

Pengembangan kewirausahaan untuk meningkatkan ekonomi masyarakat melalui pendidikan nonformal. Program pendidikan nonformal yang pada dasarnya adalah proses pemberdayaan masyarakat diharapkan menjadi titik awal untuk meningkatkan kesejahteraan masyarakat. Upaya mengatasi persoalan tersebut, diperlukan model Pemberdayaan Masyarakat untuk meningkatkan Kewirausahaan Usaha Mandiri dan pada akhirnya mampu meningkatkan status sosial ekonominya.

Menciptakan wirausaha (Entrepreneurship) yang tangguh tidaklah mudah, karena diperlukan prasyarat-prasyarat tertentu, di antaranya adalah mampu menatap masa dengan lebih baik, memiliki orientasi kreatif dan perspektif (Mulyono, 2015).

Dengan demikian maka sebaiknya dalam pengembangan sumber daya perempuan sebaiknya diarahkan untuk membentuk manusia yang (1) memiliki motivasi dan etos kerja yang tinggi, (2) menguasai banyak ilmu dan keterampilan, (3) memiliki sikap mental yang konsisten yang diwujudkan dalam komitmennya 


\section{INTEGRITAS : Jurnal Pengabdian}

Vol 4, No 1, Juli 2020

ISSN 2580 - 7978 (cetak) ISSN 2615 - 0794 (online)

pada bidang pekerjaan tertentu (profesional), (4) memiliki semangat dan kemampuan bersaing (kompetitif), dan (5) memiliki budaya yang didasari pada nilai-nilai agama dan humanisme (Nurwahidah, n.d.).

Berdasarkan hasil pengamatan yang dilakukan di Desa Lipumangau Kecamatan Sampolawa Kabupaten Buton Selatan masalah utama yang di hadapi adalah perempuan putus sekolah cukup tinggi serta tidak memiliki keterampilan. Melihat situasi permasalahan tersebut di atas maka kami melaksanakan kegiatan Pengabdian Kepada Masyarakat (PKM) di Desa Lipumangau Kecamatan Sampolawa Kabupaten Buton Selatan.

Kegiatan PKM ini dilaksanakan oleh dosen Universitas Muhammadiyah Buton. Kegiatan pengabdian ini tidak hanya sebagai perwujudan tanggung jawab dosen untuk melaksanakan tanggung jawab dalam hal tridharma perguruan tinggi yang dilaksanakan rutin setiap tahun pada masyarakat, melainkan juga sebagai sebuah kegiatan yang memberikan pengalaman kepada masyarakat khusunya perempuan. Kegiatan ini tentunya akan menambah wawasan sekaligus melengkapi keterampilan dosen.

Kegiatan pengabdian kepada masyarakat (PKM) ini diselenggarakan di Desa Lipumangau Kecamatan Sampolawa Kabupaten Buton Selatan, adapun tujuan dari pengabdian kepada masyarakat ini ialah:

1. Memberikan bekal pengetahuan kepada peserta Keaksaraan Usaha Mandiri.

2. Memberikan bekal keterampilan kepada peserta Keaksaraan Usaha Mandiri melalui pembelajaran keterampilan.

\section{METODE PELAKSANAAN}

Metode yang digunakan merupakan metode pemberdayaan masyarakat yang terdiri dari Ceramah, Curah Pendapat, Diskusi. Adapun populasinya adalah warga Desa Lipumangau khususnya perempuan. Kegiatan pengabdian ini dilaksanakan dalam bentuk penyuluhan dengan pendampingan, kegiatan ini dilaksanakan pada tanggal 15 Februari 2020. 


\section{INTEGRITAS : Jurnal Pengabdian}

Vol 4, No 1, Juli 2020

ISSN 2580 - 7978 (cetak) ISSN 2615 - 0794 (online)

Adapun output yang menjadi target dalam pengabdian ini adalah Peserta Keaksaraan Usaha Mandiri mempunyai bekal pengetahuan dan keterampilan.

\section{HASIL DAN PEMBAHASAN}

Kegiatan pengabdian kepada masyarakat ini dilaksanakan di Desa Lipumangau Kecamatan Sampolawa Kabupaten Buton Selatan. Adapun tahapan pelaksanaan kegiatan pengabdian pada masyarakat secara lengkap dapat dilihat pada Tabel berikut:

Tabel 1. Tahapan Kegiatan Pengabdian

\begin{tabular}{|c|c|c|c|}
\hline No & Tahapan Kegiatan & $\begin{array}{l}\text { Metode yang } \\
\text { Digunakan }\end{array}$ & Keterangan \\
\hline 1 & $\begin{array}{l}\text { Survey dan } \text { Penetapan } \\
\text { Wilayah Mitra }\end{array}$ & Pertemuan dan diskusi & $\begin{array}{l}\text { Tim PKM, kepala } \\
\text { desa, dan aparatur } \\
\text { perangkat desa }\end{array}$ \\
\hline 2 & $\begin{array}{l}\text { Melakukan koordinasi tim } \\
\text { guna penyelenggaraan } \\
\text { kegiatan pengabdian kepada } \\
\text { masyarakat }\end{array}$ & Pertemuan dan diskusi & $\begin{array}{lr}\text { Tim PKM, kepala } \\
\text { desa, } & \text { dan } \\
\text { masyarakat } & \end{array}$ \\
\hline 3 & $\begin{array}{l}\text { Kegiatan Pengabdian pada } \\
\text { masyarakat dilaksanakan } \\
\text { melalui penyuluhan dan } \\
\text { pelatihan }\end{array}$ & Pertemuan dan diskusi & $\begin{array}{l}\text { Tim PKM dan } \\
\text { masyarakat }\end{array}$ \\
\hline
\end{tabular}

meningkatkan Kewirausahaan Usaha Mandiri di Desa Lipumangau memberikan pendidikan keaksaraan usaha mandiri untuk meningkatkan kemampuan atau keterampilan dasar usaha yang dilatihkan melalui pembelajaran produktif dan keterampilan bermata pencaharian yang dapat meningkatkan keaksaraan dan penghasilan, baik secara perorangan maupun kelompok sebagai salah satu upaya penguatan keaksaraan sekaligus pengentasan kemiskinan.

Uraian kegiatan pemberdayaan perempuan dalam meningkatkan keaksaraan usaha mandiri yang dilaksanakan adalah sebagai berikut:

1. Sosialisasi 


\section{INTEGRITAS : Jurnal Pengabdian}

Vol 4, No 1, Juli 2020

ISSN 2580 - 7978 (cetak) ISSN 2615 - 0794 (online)

Sosialisasi dalam meningkatkan keaksaraan usaha mandiri merupakan kegiatan yang sangat penting, hal tersebut karena keaksaraan pada umumnya masih asing bagi sebagian masyarakat yang berada pada kawasan daerah tertinggal dan terkebelakang atau daerah terpencil. Sosialisasi dimaksudkan untuk memperkenalkan program Keaksaraan Usaha Mandiri kepada masyarakat dan sasaran terkait dengan pelaksanaannya. Khusus kepada warga disosialisasikan bagaimana bentuk kegiatannya, cara pelaksaaannya, siapa yang melaksanakan, berapa lama berlangsung, apa saja yang menjadi hak dan kewajiban warga dalam mengikuti kegiatan PKM. Sosialisasi dilaksanakan beberapa kali, agar kegiatan Keaksaraan Usaha Mandara dapat dipahami dan dimengerti oleh masyarakat sebagai sasaran. Selain itu, agar kegiatan ini mendapat dukungan dan support dari pemerintah setempat.

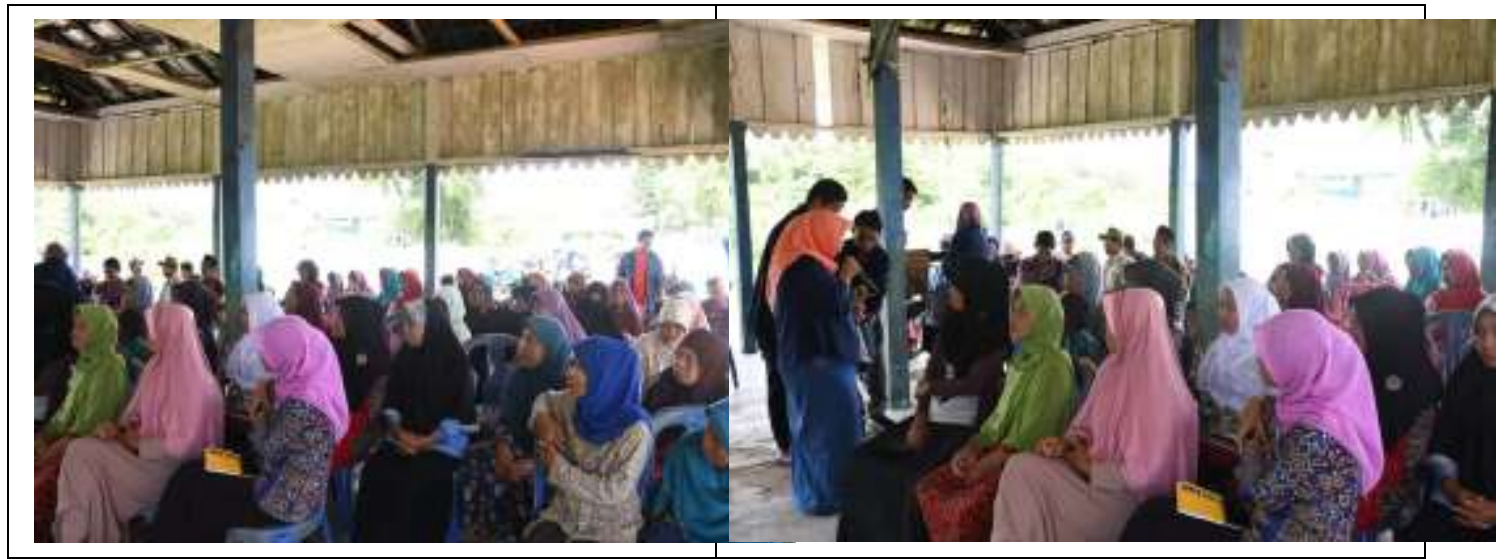

Gambar 1. Sosialisasi PKM Tentang Pemberdayaan Perempuan Dalam Meningkatkan

Keaksaraan Usaha Mandiri

2. Pelaksanaan Kegiatan

Dalam melaksanakan kegiatan pemberdayaan perempuan dalam meningkatkan keaksaraan usaha mandiri pertama-tama dilakukan persiapan pembelajaran, kegiatan ini meliputi:

a. Penyiapan rencana dan jadwal kegiatan yang dituangkan dalam Acuan Pelaksanaan.

b. Sosialisasi dan koordinasi pelaksanaan kegiatan. 


\section{INTEGRITAS : Jurnal Pengabdian}

Vol 4, No 1, Juli 2020

ISSN 2580 - 7978 (cetak) ISSN 2615 - 0794 (online)

Setelah itu Pelaksanaan Pembelajaran, untuk pelaksanaan pembelajaran mengacu pada Standar Kompetensi Keaksaraan Usaha Mandiri. Setiap kelompok belajar minimal 10 peserta didik.

Setelah itu penyelenggaraan bersama Tim PKM dan peserta, membuat kesepakatan (kontrak belajar). Kontrak belajar mencakup jadwal, tempat, waktu dan tata tertib.

Setelah itu melaksanakan kegiatan pembelajaran/keterampilan dasar usaha. Kegiatan tersebut dilakukan secara terstruktur yaitu mengungkapkan keinginan berusaha berdasarkan minat dan potensi yang tersedia, mempraktikkan sebuah keterampilan yang berpeluang menjadi bidang usaha sesuai minat dan potensi yang dimiliki, menyusun rancangan usaha dan menjalankan usaha mandiri yang dikembangkan, merancang dan mengelola biaya pada usaha yang akan dikembangkan, mengidentifikasi risiko-risiko yang mungkin timbul dan mempengaruhi laba rugi usaha, memahami strategi pemasaran, mengenali kekuatan pesaing dalam pasar produk yang dikembangkan, menjalin kemitraan, dan menjaga kelangsungan usaha yang dikembangkan.

Materi dalam kegiatan PKM pemberdayaan perempuan dalam meningkatkan keaksaraan usaha mandiri yaitu:

\begin{tabular}{|l|l|l|}
\hline \multicolumn{1}{|c|}{ Metode } & $:$ & Ceramah, Curah Pendapat, Diskusi \\
\hline Kegiatan & $:$ & $\begin{array}{l}\text { Kegiatan Pendahuluaan. } \\
\text { Pembelajaran }\end{array}$ \\
& $\begin{array}{l}\text { 1. Pembukaan dan salam } \\
\text { 2. Apersepsi materi (membrikan gambaran materi yang akan } \\
\text { dibahas/dipelajari) } \\
\text { 3. Pemberian motivasi kepada warga belajar agar mereka memiliki } \\
\text { kesiapan belajar. } \\
\text { 4. Pemberian petunjuk/acuan belajar kepada warga belajar. } \\
\text { Kegiatan Inti Pembelajaran. } \\
\text { 1. Menjelasakan jenis bidang-bidang usaha yang berpeluang untuk } \\
\text { dikembangkan. }\end{array}$ \\
\hline
\end{tabular}




\section{INTEGRITAS : Jurnal Pengabdian}

Vol 4, No 1, Juli 2020

ISSN 2580 - 7978 (cetak) ISSN 2615 - 0794 (online)

\begin{tabular}{|c|c|c|}
\hline & & $\begin{array}{l}\text { 2. Curah pendapat, tanya jawab dan penjelasan minat dan } \\
\text { keterampilan yang dimiliki warga belajar. } \\
\text { 3. Diskusi dan tanya jawab bidang usaha yang sesuai dengan minat } \\
\text { dan keterampilan warga belajar yang memungkinkan untuk } \\
\text { dikembangkan. } \\
\text { 4. Menjelaskan cara menentukan pilihan jenis bidang usha yang } \\
\text { sesuai dengan minat dan keterampilan. } \\
\text { 5. Diskusi memilih jenis usaha yang sesuai minat dan keterampilan } \\
\text { warga Belajar. } \\
\text { Kegiatan Penutup } \\
\text { 1. Diskusi, curah pendapat dan tanya jawab pelaksanaan usaha sesuai } \\
\text { minat dan keterampilan warga belajar. } \\
\text { 2. Diskusi, dan curah pendapat untuk memutuskan jenis usaha yang } \\
\text { akan dikembangkan baik secara individu maupun berkelompok. } \\
\text { 3. Diskusi, curah pendapat dan tanya jawab menyusun persiapan - } \\
\text { persiapan pelaksanaan kegiatan usaha sesuai minat dan } \\
\text { keterampilan usaha. } \\
\text { 4. Menyimpulkan kesepakatan tentang jenis usha yang akan } \\
\text { dikembangkan. }\end{array}$ \\
\hline Sumber Belajar & : & Buku - buku pengembangan dan pemilihan usaha. \\
\hline Materi belajar & & $\begin{array}{l}\text { 1. Minat dan keterampilan usaha yang dimiliki warga belajar. } \\
\text { 2. Mengidentifikasi bidang-bidang usaha yang berpotensi untuk } \\
\text { dikembangkan. } \\
\text { 3. Bidang-bidang usaha yang sesuai dengan minat dan } \\
\text { keterampilan warga belajar. } \\
\text { 4. Teknik memilih bidang usaha yang sesuai minat dan } \\
\text { keterampilan. } \\
\text { 5. Perencanaan kegiatan usaha }\end{array}$ \\
\hline
\end{tabular}




\section{INTEGRITAS : Jurnal Pengabdian}

Vol 4, No 1, Juli 2020

ISSN 2580 - 7978 (cetak) ISSN 2615 - 0794 (online)

\section{KESIMPULAN}

Berdasarkan kegiatan pengabdian tentang Pemberdayaan Perempuan dalam Meningkatkan Keaksaraan Usaha Mandiri, mulai dari awal pelaksanaan yakni survey penetapan desa mitra, pelaksanaan kegiatan penyampaian materi pemberdayaan perempuan dalam meningkatkan keaksaraan usaha mandiri, dapat disimpulkan bahwa kegiatan pengabdian seperti ini sangat dinantikan oleh warga belajar khususnya perempuan usia 15-49 tahun dalam upaya pengembangan dan pemilihan usaha. Perempuan usia 15-49 tahun yang menjadi target sasaran kegiatan pengabdian ini begitu antusias mengikuti kegiatan penyampaian materi melalui ceramah dan diskusi.

\section{DAFTAR PUSTAKA}

Hening Ratri. (2015). Pelaksanaan Program Keaksaraan Usaha Mandiri (Kum) Dengan Pemberdayaan Masyarakat Di Pkbm Handayani Dea Baureno Kecamatan Baureno Kabupaten Bojonegoro. J+Plus Unesa, 4(1), 1-11. https://jurnalmahasiswa.unesa.ac.id/index.php/jurnal-pendidikan-luarsekolah/article/view/13236

Karwati, L. (2017). Pemberdayaan Perempuan Melalui Pelatihan Woman Empowerment Through Entrepreneurs Training. Jurnal Ilmiah Visi PGTK PAUD Dan Dimas, 12(1), 45-52. https://media.neliti.com/media/publications/259938-pemberdayaanperempuan-melalui-pelatihan-5d1ad68b.pdf

Nainggolan, D. Y. (2013). PEMBERDAYAAN DAN PENGEMBANGAN WIRAUSAHA PEREMPUAN MUDA PADA RUMAH TANGGA MISKIN DI KECAMATAN MEDAN DELI KOTA MEDAN. JURNAL ILMU SOSIAL-FAKULTAS ISIPOL UMA, 6(April), 14-29.

Nurwahidah, H. L. S. (n.d.). PEMBERDAYAAN PEREMPUAN MELALUI PEMBELAJARAN LITERASI BERORIENTASI KEAKSARAAN USAHA MANDIRI. Jurnal Ilmiah Program Studi Pendidikan Bahasa Dan Sastra Indonesia, 55-67.

Mulyono, S. E. (2015). Model Pemberdayaan Masyarakat Untuk Peningkatan Literasi Berbasis Kewirausahaan Usaha Mandiri Melalui Pkbm Di Kota Semarang. Journal of Nonformal Education, 1(1). https://doi.org/10.24914/pnf.v1i1.3983 